\title{
Review on the construction development and control technology of the shaking table
}

\author{
Chunhua Gao \\ Associate Professor, College of Architecture and Civil Engineering, Xinyang \\ Normal University, Xinyang, China (corresponding author: \\ 285394739@qq.com) \\ Jieqiong Wang \\ Postgraduate student, College of Architecture and Civil Engineering, \\ Xinyang Normal University, Xinyang, China \\ Xiaobo Yuan \\ Postgraduate student, College of Architecture and Civil Engineering, \\ Xinyang Normal University, Xinyang, China
}

\author{
Yonghe Zhang \\ Postgraduate student, College of Architecture and Civil Engineering, \\ Xinyang Normal University, Xinyang, China \\ Yanping Yang \\ Postgraduate student, College of Architecture and Civil Engineering, \\ Xinyang Normal University, Xinyang, China \\ Mengyuan Qin \\ Postgraduate student, College of Architecture and Civil Engineering, \\ Xinyang Normal University, Xinyang, China
}

The shaking table is a good reproduction of the structure response test method in the laboratory. This paper explores the shaking or vibration table from the aspects of construction, control technology, test method and application. The construction time of a typical shaking table in China and around the world is given, and the indicators such as table size and performance parameters are hereto summarised. This paper expounds the significance of the construction of the shaking table, analyses its development and the advantages and disadvantages of its control technology, and discusses its existing mainstream test methods and application process. The application of the shaking table technology in related research fields is introduced in detail. This provides a reference for the further selection, upgrade, development and utilisation of seismic research simulation of shaking table.

Keywords: construction/control technology/shaking table/test method and application

\section{Introduction}

It is well-known that earthquake is one of the most dangerous disasters on earth, making seismic research urgent. According to Huang (2008), seismic test is the most important step in seismic research. The shaking table test is favoured by researchers because it can effectively reproduce seismic waves on the table during the experimental process and intuitively understand the seismic performance of structures. Nowadays, the type and size of the shaking table have changed greatly. Control technology has developed from classical analogue control to intelligent control. However, due to the performance difference of the internal components of the shaking table and other factors, the reproduction accuracy of the shaking table waveform is limited (Tang et al., 2009). To further promote the overall stability of a shaking table, to increase its robustness in the process of experiment and to improve the precision of mesa waveform reproduction, some scholars, in recent years, have studied in detail the dynamic characteristics of its main components, performance parameters, interaction, and so on. They have established a powerful control theory research system for the shaking table system. Shaking tables have also been widely applied in various fields of seismic research direction. In view of the limited literature on the construction, control, application and development of shaking tables in China and internationally, this paper will comprehensively analyse and summarise the shaking table from the aspects mentioned here according to existing relevant information, so as to provide reference for the further development of research on shaking tables in the future.

\section{Construction of a shaking table}

\subsection{International construction conditions}

The shaking table was developed in Japan and in the United States in the mid-1960s (Huang, 1986; Wang, 2009; Williams, 2001). The development of early Japanese and American shaking tables is shown in Table 1. With the deepening of seismic research, it has become inevitable to develop large vibration tables and vibration systems. Studies on the large-scale and multiple arrays of typical shaking tables internationally are shown in Table 2. The E-Defense shaking table (Ling, 2008) is shown in Figure 1, which has a maximum load of $1200 \mathrm{t}$, a maximum displacement of $\pm 1000 \mathrm{~mm}$ and a power output of up to $6000 \mathrm{kN}$.

\subsection{Domestic construction situation}

Research on shaking tables started relatively late in China, and relevant research progress of the early shaking table in China is shown in Table 3. The typical Chinese seismic simulation vibration tables before the year 2000 is summarised in the work of Gao et al. (2014). Since the beginning of the twenty-first century, the research on large-scale shaking tables and array systems in China has also been in full swing. The relevant construction situation is shown in Table 4.

The multifunctional shaking table test system built by Tongji University is shown in Figure 2. Four desks can synthesise a large linear shaking table group and can also be two parallel syntheses of a large rectangular shaking table group. Two main platforms 
Table 1. The early development of shaking tables in Japan and USA

\begin{tabular}{|c|c|c|c|c|c|}
\hline $\begin{array}{l}\text { Time } \\
\text { (year) }\end{array}$ & Developer & $\begin{array}{c}\text { Platform } \\
\text { dimension: } m\end{array}$ & Direction & Contribution & Reference \\
\hline 1966 & $\begin{array}{l}\text { Institute of Production Technology, } \\
\text { University of Tokyo }\end{array}$ & $10 \times 2$ & $x$ & The world's first & $\begin{array}{l}\text { Huang } \\
(1986)\end{array}$ \\
\hline 1968 & University of Illinois & $3.65 \times 3.65$ & x & The United States' first & Wang \\
\hline 1970 & $\begin{array}{l}\text { Japan's National Disaster Prevention } \\
\text { Center }\end{array}$ & $15 \times 15$ & $\mathrm{X}$ or Z & The world's first biggest (from 1970 to 2020) & $\begin{array}{r}(2009) \\
\text { Williams }\end{array}$ \\
\hline 1971 & University of California, Berkeley & $6.10 \times 6.10$ & $X, Y$ & World's first two-way machine & (2001) \\
\hline 1984 & Mitsubishi Corporation & $6 \times 6$ & $X, Y, Z$ & $\begin{array}{l}\text { The three-parameter control technology is } \\
\text { used for the first time }\end{array}$ & \\
\hline
\end{tabular}

Table 2. Study on the large-scale and multiple arrays of typical shaking tables outside China

\begin{tabular}{|c|c|c|c|c|}
\hline $\begin{array}{l}\text { Time } \\
\text { (year) }\end{array}$ & $\begin{array}{l}\text { Development } \\
\text { organisation }\end{array}$ & $\begin{array}{c}\text { Platform } \\
\text { dimension: } m\end{array}$ & Direction & Significance \\
\hline 1979 & $\begin{array}{l}\text { Institute of } \\
\text { Civil } \\
\text { Engineering, } \\
\text { Ministry of } \\
\text { Construction, } \\
\text { Japan }\end{array}$ & $\begin{array}{c}\text { Four series of } \\
\quad 3 \times 2\end{array}$ & $x$ & $\begin{array}{l}\text { The earliest } \\
\text { array } \\
\text { system in } \\
\text { the world }\end{array}$ \\
\hline \multirow[t]{2}{*}{$\begin{array}{l}\text { The } \\
\text { 1990s }\end{array}$} & $\begin{array}{l}\text { The French } \\
\text { Laboratory of } \\
\text { Seismic } \\
\text { Mechanic } \\
\text { Studies }\end{array}$ & $7.60 \times 7.60$ & $X, Y, Z$ & $\begin{array}{l}\text { The largest } \\
\text { shaking } \\
\text { table in } \\
\text { Europe in } \\
\text { the } \\
\text { twentieth } \\
\text { century }\end{array}$ \\
\hline & $\begin{array}{l}\text { University of } \\
\text { California San } \\
\text { Diego }\end{array}$ & $7.60 \times 12.20$ & $x$ & $\begin{array}{l}\text { The world's } \\
\text { first and } \\
\text { largest } \\
\text { outdoor } \\
\text { shaking } \\
\text { table }\end{array}$ \\
\hline 2003 & $\begin{array}{l}\text { University of } \\
\text { Nevada, } \\
\text { Reno, USA }\end{array}$ & $\begin{array}{c}\text { Three series of } \\
4.30 \times 4.50\end{array}$ & $X, Y$ & $\begin{array}{l}\text { The first two- } \\
\text { way } \\
\text { vibration } \\
\text { system in } \\
\text { the United } \\
\text { States }\end{array}$ \\
\hline 2005 & $\begin{array}{l}\text { NIED with the } \\
\text { Department } \\
\text { of Science } \\
\text { and } \\
\text { Technology, } \\
\text { Japan }\end{array}$ & $20 \times 15$ & $X, Y, Z$ & $\begin{array}{l}\text { The largest } \\
\text { single } \\
\text { shaking } \\
\text { table in the } \\
\text { world } \\
\text { ('E-Defense } \\
\text { shaking } \\
\text { table' for } \\
\text { short) }\end{array}$ \\
\hline
\end{tabular}

(B, C) can also be integrated into a large vibration table as a single vibration table based on the shaking table laboratory information sharing service platform of Tongji University (2021). The underwater shaking table system of Tianjin University is the world's first underwater three-directional 6 degrees of freedom twin shaking table array as shown in Figure 3 (Zhao and Chen, 2019). Tianjin University's large shaking table system will surpass 'E-Defense' to be the largest in the world once completed.

\section{Shaking table control technology}

3.1 Traditional control and improvement methods The traditional shaking table control method is mainly divided into displacement control-based PID control and 'three-parameter control' and is reviewed in the works of Cai (2018) and Wan et al. (2012). By comparing the simulation results of PID control and threeparameter control, Chen and Zhang (2013) pointed out that the threeparameter control technology can effectively increase the system damping ratio and prevent excessive resonance damage of specimens, and can also increase system stability. Also, some scholars (Gao et al., 2014; Luan et al., 2014a, 2014b; Tagawa and Kajiwara, 2007; Wang et al., 2007; Xu et al., 2008; Yang et al., 2007) also conducted in-depth studies on the three-parameter control technology successively. Ji et al. (2012) solved the inconvenience in the design and application of an analogue speed synthesiser and developed a new type of speed synthesiser. The simulation model of the synthesiser is shown in Figure 4.

For the problem of parameter tuning in three-parameter control, a 'three-parameter improved control algorithm' based on the combination of three-parameter feedforward and feedback is proposed in Luan et al. (2014a, 2014b), which effectively eliminated the poles close to the virtual axis in the closed-loop transmission function of the system and widened the system bandwidth. The principal diagram is shown in Figure 5. Li et al. (2018) introduced acceleration feedback into the improved three-parameter control algorithm, enlarging the system bandwidth to $0.35-64 \mathrm{~Hz}$. The transmission function is shown in Figure 6.

\subsection{Intelligent control algorithm}

Since the 1970s, iterative algorithm has been applied to the control of seismic simulation shaker (Tang et al., 2009). The three-parameter control technology based on linear iterative correction could better reproduce the acceleration time history. However, the pre-test will cause some damage to the specimen. Then the adaptive control algorithm was born; this algorithm can eliminate the disadvantage of non-adjustable parameter ratio in traditional control without needing to master the mathematical model of the controlled object, and it has a better fault tolerance ability. The model reference adaptive control (MRAC), adaptive inverse control and other algorithms are derived (Zhang et al., 2013). Tian et al. (2012) proposed an improved adaptive control test method, which can identify the system transmission 


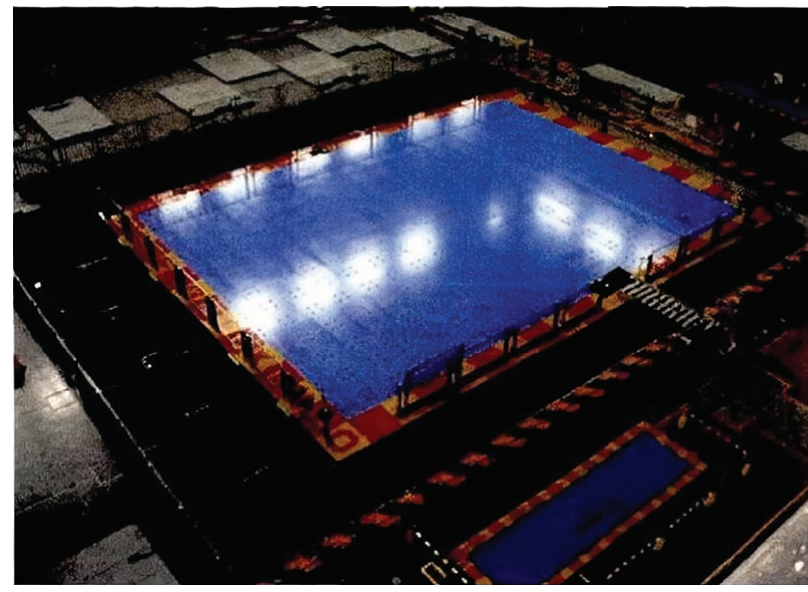

(a)

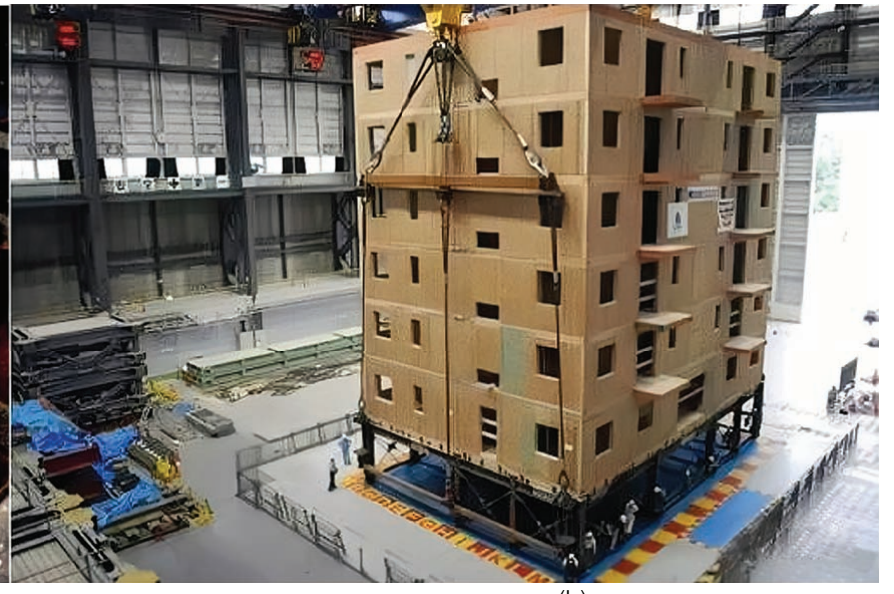

(b)

Figure 1. Shaking table and seismic experimental research site: (a) the shaking table and (b) the model

Table 3. Research progress of shaking tables in China

\begin{tabular}{|c|c|}
\hline $\begin{array}{l}\text { Time } \\
\text { (year) }\end{array}$ & Achievement \\
\hline 1969 & $\begin{array}{l}\text { The first special shaking table for the national defense } \\
\text { system was successfully built. }\end{array}$ \\
\hline 1986 & $\begin{array}{l}\text { A } 3 \times 3 \text { m single horizontal vibration table with double } \\
\text { shakers was developed. }\end{array}$ \\
\hline 1988 & $\begin{array}{l}\text { A } 5 \times 5 \text { m double horizontal seismic simulation } \\
\text { shaking table was successfully developed. }\end{array}$ \\
\hline 1997 & $\begin{array}{l}\text { The Institute of Engineering Mechanics of China } \\
\text { Earthquake Administration and Harbin Institute of } \\
\text { Technology jointly and successfully developed a } 5 \times \\
5 \mathrm{~m} \text { three-way } 6 \text { degrees of freedom shaking table. }\end{array}$ \\
\hline
\end{tabular}

function in real time and directly obtain the initial system transmission function, thus avoiding the damage caused by the specimen pre-test, and having strong tracking ability and anti-interference ability. Cai (2018) also proposed a dual-loop control algorithm combining MRAC and three-variable control (TVC), as shown in Figure 7. This algorithm increases the robustness of the system and reduces tracking error. It also weakens the adverse transient response caused by the change of initial parameters to the system, accelerates the convergence speed, widens the bandwidth and improves the stability of the system.

Besides the control algorithms, other forms of intelligent control algorithms have been gradually applied to the field of shaking table control. Peng (2018) proposed a neural control method based on wavelet network and applied it to the control research of turntable servo system. The results show that the method can effectively improve the accuracy of the controlled system. Soleymani et al. (2019) designed a fuzzy sliding mode supervisory controller for a shaking table with a variable load. The controller consists of a proportional interval latent rule controller and a fuzzy-sliding mode monitoring controller. The experimental results show that the controller has good and robust tracking performance under harmonic and seismic excitation with parameter uncertainties.
For the parameter tuning and error compensation control system, many scholars have done in-depth research. Ji et al. (2014) proposed a self-tuning method for the control parameters of a shaking table based on his expert experience. By comparing it with the time-domain characteristics of the theoretical calculation parameter tuning method, the results show that this method is simplified and effective. A series of studies on the influence of specimen characteristics on system control performance had been conducted (Li et al., 2010; Li et al., 2019; Tang et al., 2010), and pointed out that the system had the best stability under the control of no-load design parameters, but the reproduction accuracy of input wave would be reduced to varying degrees near each order frequency point of the specimen. Therefore, a real-time reaction compensation algorithm was designed to correct the adverse effects caused by the interaction between the test piece and the mesa. Wang and Lei (2020) achieved the high-precision reproduction of shaking table waveform by using linear active disturbance rejection control (LADRC). The problem of optimisation and adjustment of relevant parameters are successfully solved (Yan et al., 2016b; Xu et al., 2017) by adopting the control method of artificial fish swarm algorithm and PID neural network.

\section{Test method and technical application of the shaking table}

\subsection{Shaking table test method}

The shaking table test methods can be generally divided into two categories: substructure test method (including substructure hybrid test) and integral model test method.

Nakashima et al. (1992) published the research results of real-time substructure test of the shaking table for the first time; real-time substructure test has both the advantages of quasi-dynamic substructure test and the advantages of simulating actual earthquake action. Reinhorn et al. (2005) proposed the hybrid test method of the vibration table substructure, formulated the substructure division principle and 
Table 4. The construction status of typically large shaking tables and array systems in China since the twenty-first century

\begin{tabular}{|c|c|c|c|c|c|c|c|c|}
\hline $\begin{array}{l}\text { Time } \\
\text { (year) }\end{array}$ & Development organisation & Direction & $\begin{array}{c}\text { Mesa } \\
\text { dimension: } \mathrm{m}\end{array}$ & Load: $\mathbf{t}$ & $\begin{array}{c}\text { Maximum } \\
\text { displacement: } \\
\mathrm{mm}\end{array}$ & $\begin{array}{l}\text { Maximum } \\
\text { speed: } \\
\mathrm{mm} / \mathrm{s}\end{array}$ & $\begin{array}{l}\text { Maximum } \\
\text { acceleration: } \\
\mathbf{g}\end{array}$ & $\begin{array}{l}\text { Frequency } \\
\text { range: } \mathrm{Hz}\end{array}$ \\
\hline 2004 & $\begin{array}{l}\text { Institute of Earthquake } \\
\text { Engineering, China Academy of } \\
\text { Building Research }\end{array}$ & $X, Y, Z$ & $6.10 \times 6.10$ & 60 & $\begin{array}{l}X: \pm 150 \\
Y: \pm 250 \\
Z: \pm 100\end{array}$ & $\begin{array}{l}X: \pm 1000 \\
Y: \pm 1200 \\
Z: \pm 800\end{array}$ & $\begin{array}{l}X: \pm 1.5 \\
Y: \pm 1.0 \\
Z: \pm 0.8\end{array}$ & $0.1-50$ \\
\hline 2006 & Beijing University of Technology & $\begin{array}{c}X \\
X, Y, Z\end{array}$ & $\begin{array}{l}1.00 \times 1.00(9) \\
2.50 \times 2.50(2)\end{array}$ & $\begin{array}{l}9 \times 10 \\
2 \times 10\end{array}$ & $\begin{array}{l}X: \pm 75 \\
X: \pm 125 \\
Y: \pm 125 \\
Z: \pm 100\end{array}$ & $\begin{array}{l}X: \pm 600 \\
X: \pm 600 \\
Y: \pm 600 \\
Z: \pm 500\end{array}$ & 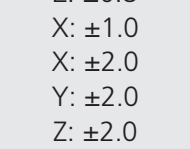 & $\begin{array}{l}0.4-50 \\
0.1-50\end{array}$ \\
\hline 2008 & Fuzhou University & $X, Y$ & $\begin{array}{c}4.00 \times 4.00 \\
2.50 \times 2.50(2)\end{array}$ & $\begin{array}{c}22 \\
10 / \text { table }\end{array}$ & $\begin{array}{l}X: \pm 250 \\
Y: \pm 250\end{array}$ & $\begin{array}{l}X: \pm 750 \\
Y: \pm 1050\end{array}$ & $\begin{array}{l}X: \pm 1.5 \\
Y: \pm 1.2\end{array}$ & $0.1-50$ \\
\hline 2011 & Tongji University & $X, Y$ & $4.00 \times 6.00(4)$ & $\begin{array}{l}\text { 30/table } \\
\text { 70/table }\end{array}$ & $\begin{array}{l}X: \pm 500 \\
Y: \pm 500\end{array}$ & $\begin{array}{l}X: \pm 1000 \\
Y: \pm 1000\end{array}$ & $\begin{array}{l}X: \pm 1.5 \\
Y: \pm 1.5\end{array}$ & $0.1-50$ \\
\hline 2013 & Central South University & $X, Y, Z$ & $4.00 \times 4.00(4)$ & 30/table & $\begin{array}{l}X: \pm 250 \\
Y: \pm 250 \\
Z: \pm 160\end{array}$ & $\begin{array}{l}X: \pm 1000 \\
Y: \pm 1000 \\
Z: \pm 1000\end{array}$ & $\begin{array}{l}X: \pm 1.0 \\
Y: \pm 1.0 \\
Z: \pm 1.6\end{array}$ & $0.1-50$ \\
\hline 2015 & Chongqing University & $X, Y, Z$ & $5.10 \times 6.10$ & 60 & $\begin{array}{l}X: \pm 250 \\
Y: \pm 250 \\
Z: \pm 200\end{array}$ & $\begin{array}{l}X: \pm 1200 \\
Y: \pm 1200 \\
Z: \pm 1000\end{array}$ & $\begin{array}{l}X: \pm 1.5 \\
Y: \pm 1.5 \\
Z: \pm 1.0\end{array}$ & $0.1-50$ \\
\hline 2017 & Southwest Jiaotong University & $X, Y, Z$ & $10.00 \times 8.00$ & 160 & $\begin{array}{l}X: \pm 800 \\
Y: \pm 800 \\
Z: \pm 400\end{array}$ & $\begin{array}{l}X: \pm 1200 \\
Y: \pm 1200 \\
Z: \pm 830\end{array}$ & $\begin{array}{l}X: \pm 1.2 \\
Y: \pm 1.2 \\
Z: \pm 1.0\end{array}$ & $0.1-50$ \\
\hline & & $X, Y, Z$ & $3.00 \times 5.00$ & 30 & $\begin{array}{l}X: \pm 400 \\
Y: \pm 400 \\
Z: \pm 400\end{array}$ & $\begin{array}{l}X: \pm 1800 \\
Y: \pm 1800 \\
Z: \pm 1500\end{array}$ & $\begin{array}{l}X: \pm 2.0 \\
Y: \pm 2.0 \\
Z: \pm 1.5\end{array}$ & $0.1-50$ \\
\hline & & $X, Y, Z$ & $3.00 \times 6.00$ & 30 & $\begin{array}{l}X: \pm 400 \\
Y: \pm 400 \\
Z: \pm 400\end{array}$ & $\begin{array}{l}X: \pm 1800 \\
Y: \pm 1800 \\
Z: \pm 1500\end{array}$ & $\begin{array}{l}X: \pm 2.0 \\
Y: \pm 2.0 \\
Z: \pm 1.5\end{array}$ & $0.1-50$ \\
\hline 2019 & Hohai University & $X, Y, Z$ & $\begin{array}{c}\phi: 5.75 \\
\text { (in water) }\end{array}$ & 20 & $\begin{array}{l}X: \pm 150 \\
Y: \pm 150 \\
Z: \pm 100\end{array}$ & $\begin{array}{l}X: \pm 1000 \\
Y: \pm 1000 \\
Z: \pm 800\end{array}$ & $\begin{array}{l}X: \pm 2.0 \\
Y: \pm 2.0 \\
Z: \pm 1.33\end{array}$ & $0.1-100$ \\
\hline 2019 & Tianjin University & $X, Y, Z$ & $\begin{array}{l}\phi: 3.60(2) \\
\text { (in water) }\end{array}$ & 20/table & $\begin{array}{l}X: \pm 300 \\
Y: \pm 300 \\
Z: \pm 200\end{array}$ & $\begin{array}{l}X: \pm 1000 \\
Y: \pm 1000 \\
Z: \pm 800\end{array}$ & $\begin{array}{l}X: \pm 1.5 \\
Y: \pm 1.5 \\
Z: \pm 1.2\end{array}$ & $0.1-100$ \\
\hline 2021 & Tianjin University (constructing) & $X, Y, Z$ & $20.00 \times 16.00$ & 1350 & - & - & $\begin{array}{l}X: \pm 1.5 \\
Y: \pm 1.5 \\
Z: \pm 2.0\end{array}$ & - \\
\hline 2021 & Southeast University (constructing) & $X, Y, Z$ & $6.00 \times 9.00$ & 120 & $\begin{array}{l}X: \pm 500 \\
Y: \pm 500 \\
Z: \pm 300\end{array}$ & $\begin{array}{l}X: \pm 1500 \\
Y: \pm 1500 \\
Z: \pm 1200\end{array}$ & $\begin{array}{l}X: \pm 1.5 \\
Y: \pm 1.5 \\
Z: \pm 1.0\end{array}$ & $0.1-50$ \\
\hline
\end{tabular}

accurately formulated the unified formula. Wang and Pan (2018) summarized the main problems in the development process of substructure hybrid test in the past three decades, and proposed the solution of "Internet + " mode, which can maximize the ability and accuracy of substructure hybrid test. "Internet + " means to connect multiple laboratory resources and realize the refinement of the "thirdgeneration extensible substructure hybrid test platform" through finite element software simulation.

The scale model test is often used in the overall structure test of the shaking table, and for such a test, it is necessary to consider dynamic similarity ratio design, model similarity requirements, model similarity constant, and so on. Zhang (1997) studied and created a set of 'uniform similarity law' for seismic simulation tests. Shen and Qian (2019) carried out the overall scale model test of seismic simulation for a high-rise frame-tube structure building. The analysis showed that the test method was reliable.
Yan et al. (2016a) designed a 1:40 full-bridge scaling model of Taizhou Yangtze River Highway Bridge and simulated the travelling wave effect, and the test results were basically consistent with the numerical calculation results. Xie and Sun (2018) conducted a scale model test on a super-long cable-stayed bridge with a main span of $1400 \mathrm{~m}$ with a similarity ratio of $1 / 70$, and realized that the soil-structure interaction had a great influence on the dynamic characteristics of the bridge, and that the high-order vibration mode had the most obvious influence on the seismic response of the main tower. The test model of superlong span cable-stayed bridge is shown in Figure 8.

\subsection{Application of the shaking table technology}

At present, the seismic simulation shaking table has been widely used in building structure engineering, bridge and tunnel engineering, geotechnical engineering, power transmission equipment engineering, atomic energy and weapons equipment 


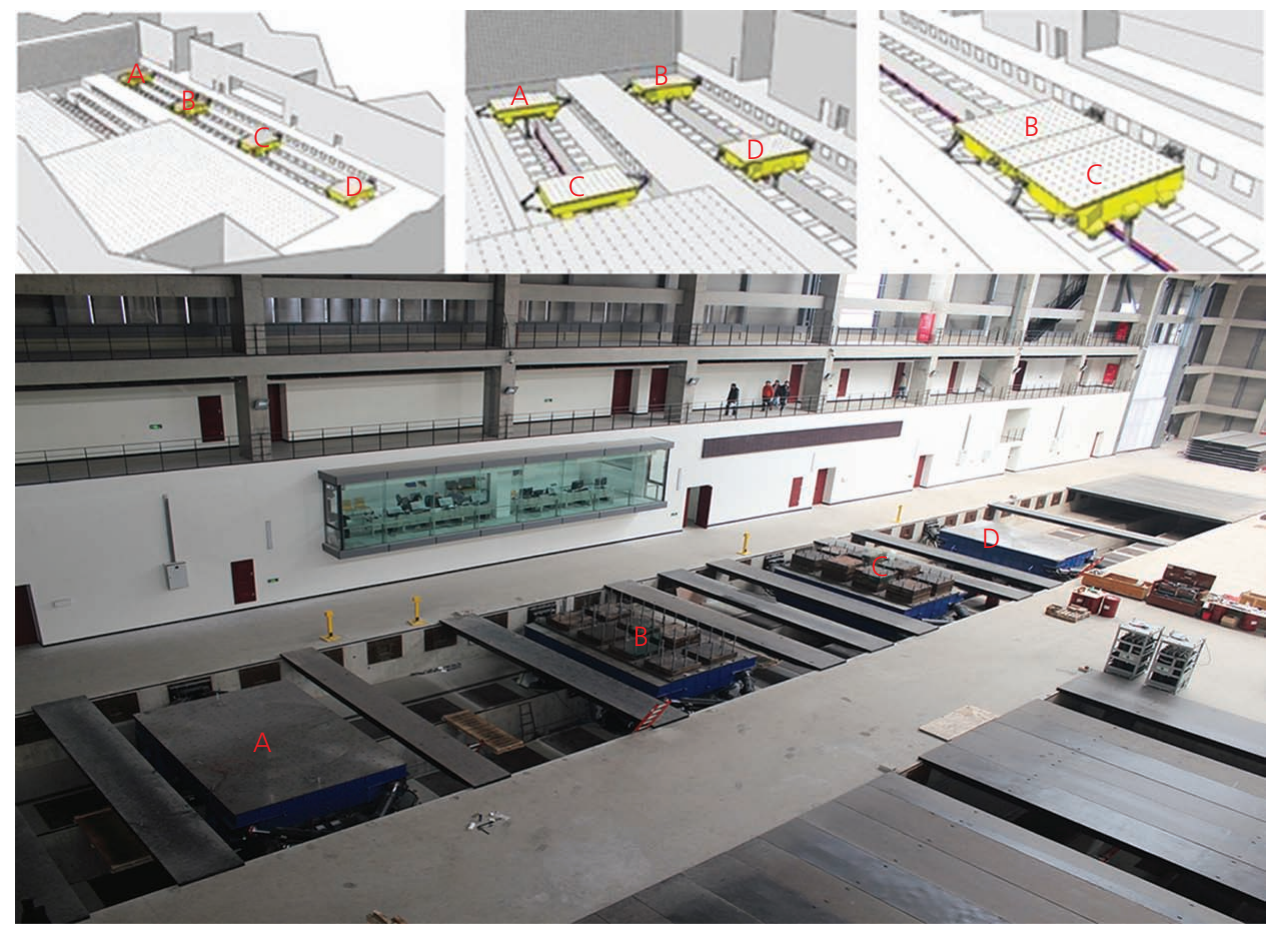

Figure 2. Multi-function shaking table experimental system of Tongji University

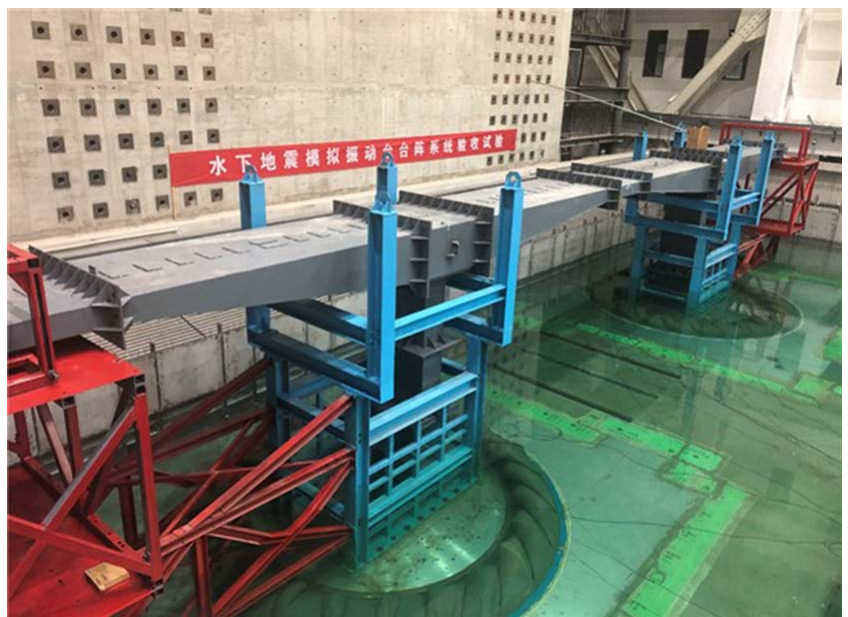

Figure 3. Underwater shaking table array system of Tianjin University

research and other fields. Shi et al. (2018) and Han et al. (2018) applied a seismic simulation shaking table test technology to the structural vibration research of nuclear power plant equipment and liquid engine, and achieved ideal results. Ma et al. (2019) found out the main causes of dynamic soil pressure change under the earthquake action through the analysis of a series of soil slope reinforcement shaking table test, the results help people to better understand the characteristics of dynamic soil pressure, and provide a basis for strengthening the slope and improving the seismic stability of the structure. Li et al. (2020) explored the failure mode of large-span subway stations under asymmetric loads through the overall scale model test of subway stations. $\mathrm{Pu}$ et al. (2020) conducted a shaking table test on the dynamic response characteristics and failure mechanism of loess slope under earthquake action, and a method of $\mathrm{S}$ value is proposed to reflect soil failure and slope failure. Kavand et al. (2021) studied the influence of liquefaction on lateral expansion of pier wharf piles by combining large-scale shaking table test and numerical simulation under $1 \mathrm{~g}$ acceleration. The results show that the bending moment is larger when the pile side expands, and the bending moment of the down-slope pile is larger than that of the up-slope pile. Yan et al. (2020) used a seismic simulation shaking table to study and analyse the seismic response of anisotropic rock slope with a soft layer by a similar model test. The casting model and bolt arrangement are shown in Figures 9 and 10. In this experiment, the strain of two anchoring interfaces under seismic action was measured and the seismic response law between the anchoring rod and mortar of slope with inclined rock mass with soft layer, was studied.

With the acceleration of infrastructure construction in China, the seismic research on shaking table plays an increasingly prominent role in road and bridge engineering and electrical engineering. Chen et al. (2020) conducted three groups of large-scale simulation tests on the slope roadbed strengthened by bored piles on the Sichuan-Tibet Railway by using a shaking table. The results show that the bored piles could significantly improve the overall stability of the roadbed, and the 
Smart Infrastructure and Construction Volume 174 Issue 1
Review on the construction development and control technology of the shaking table

Gao, Wang, Yuan et al.

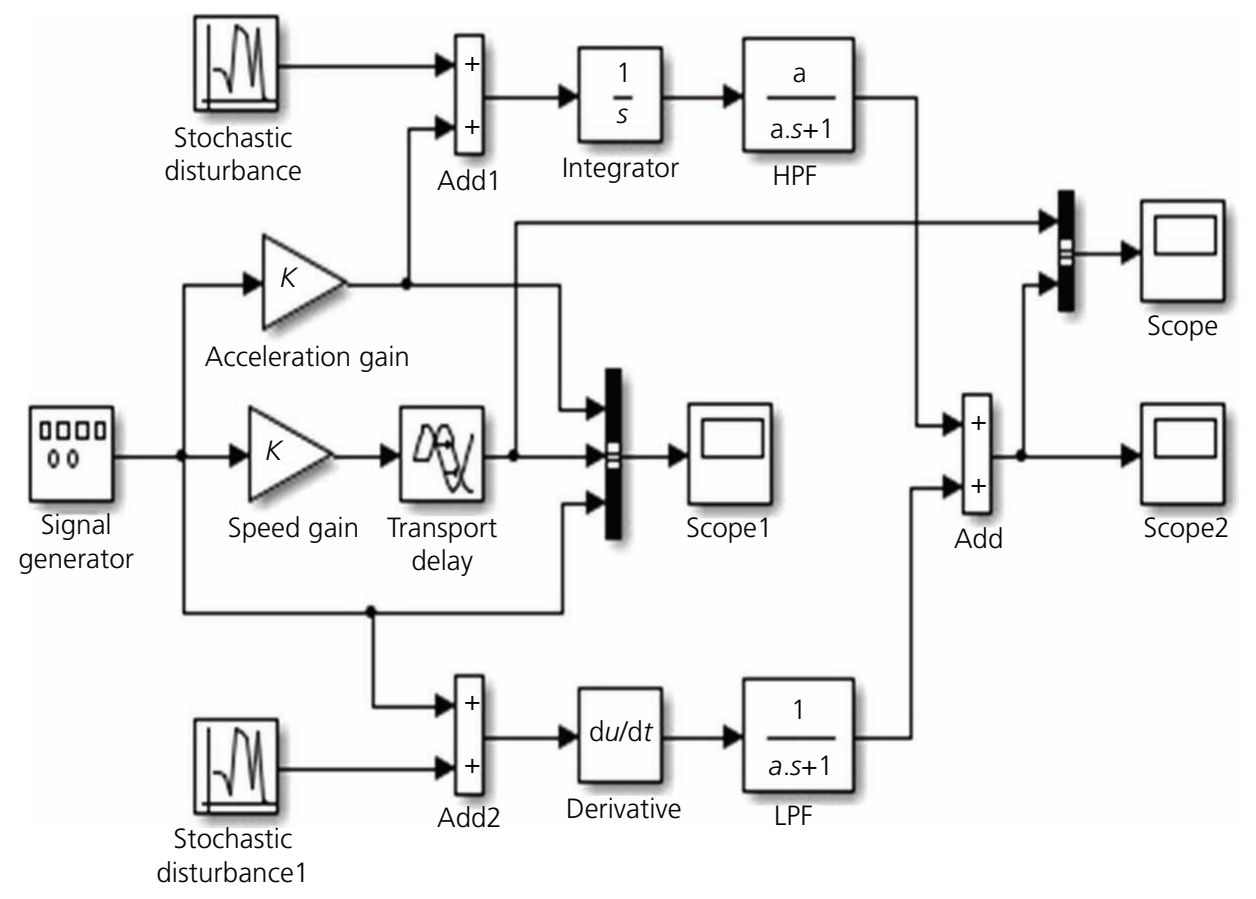

Figure 4. Simulink simulation model of the speed synthesiser

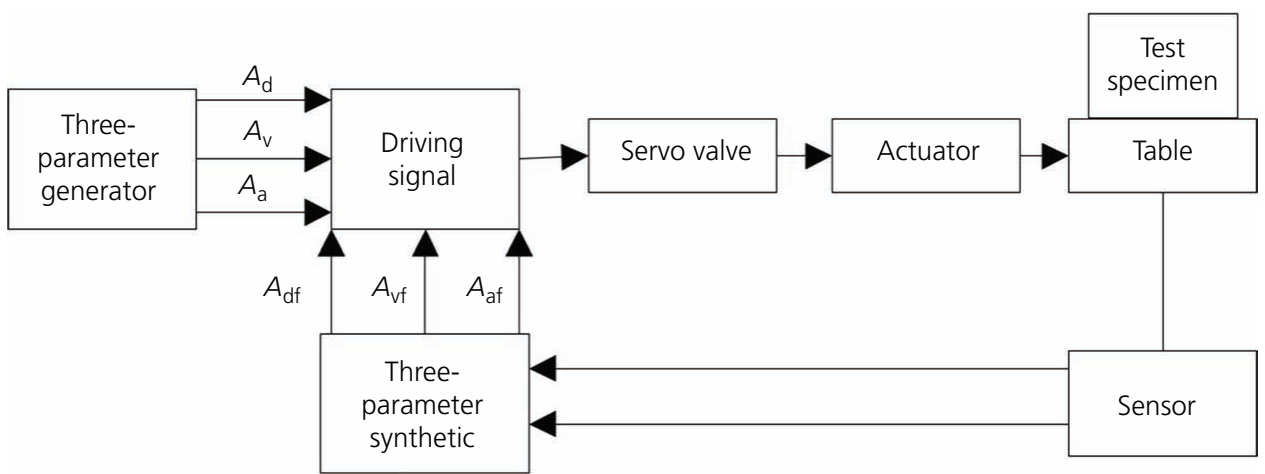

Figure 5. Control schematic diagram of the improved shaking table system

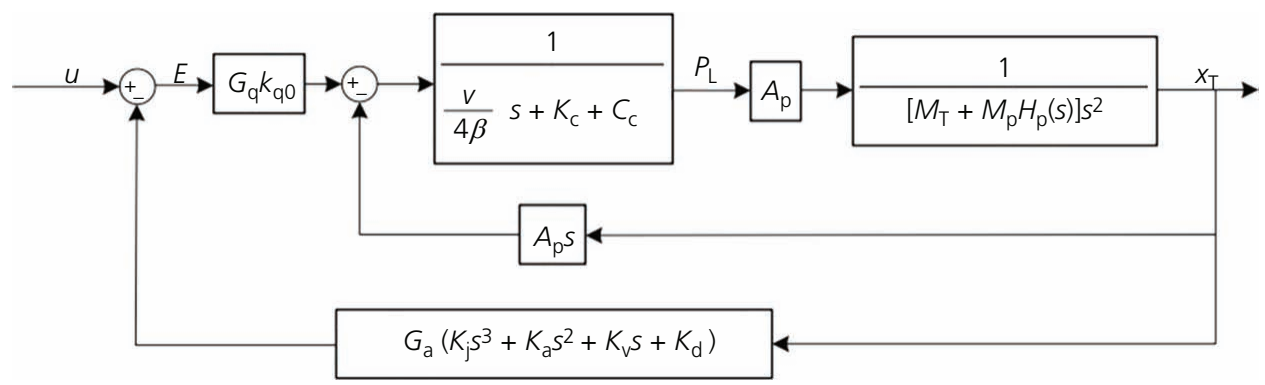

Figure 6. Transfer function diagram of the system with acceleration feedback 


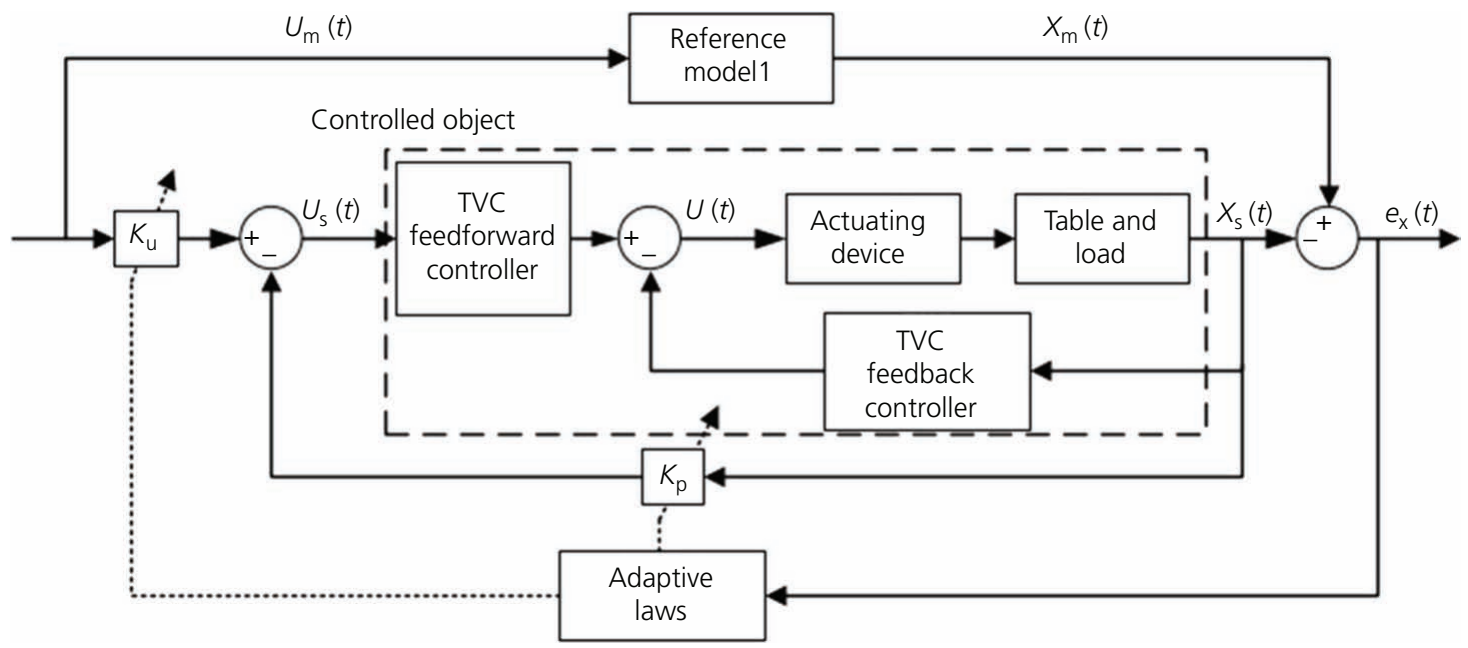

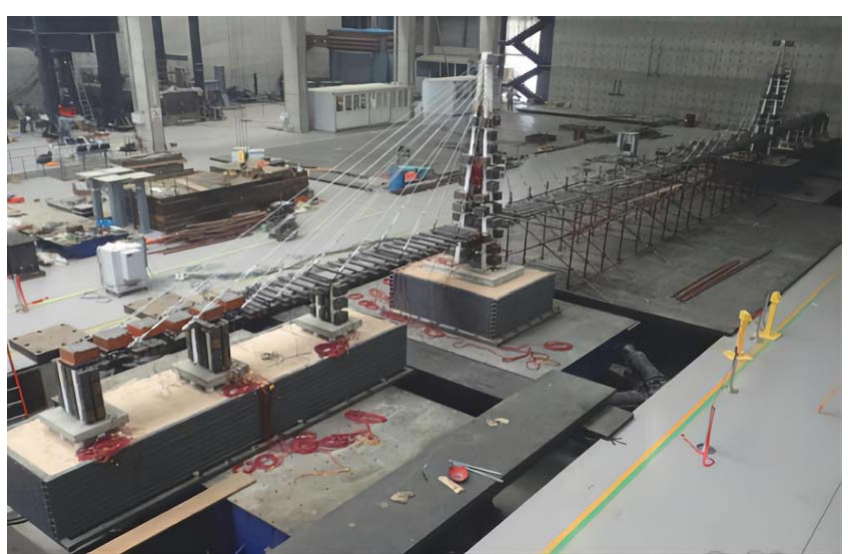

Figure 8. Test model of an ultra-large span cable-stayed bridge

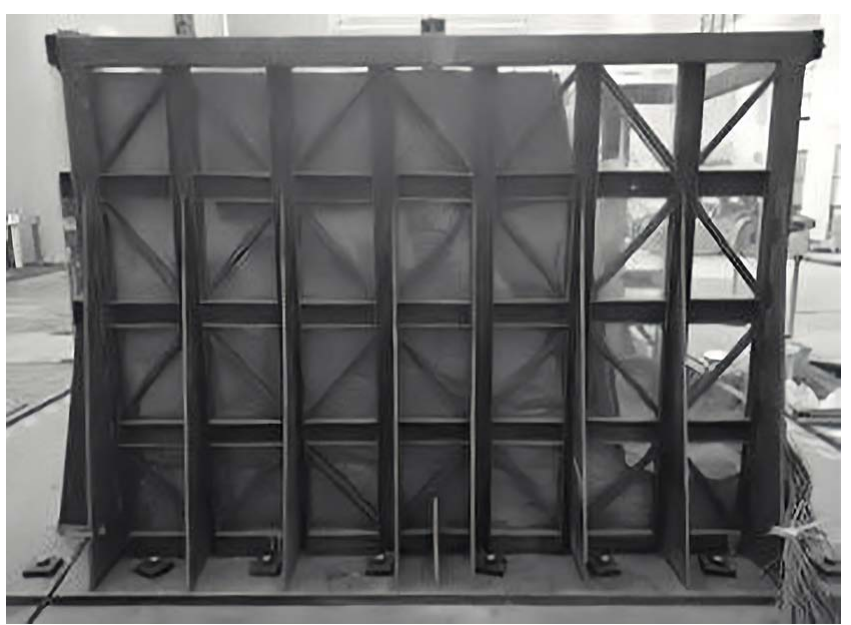

Figure 9. Mold box after casting

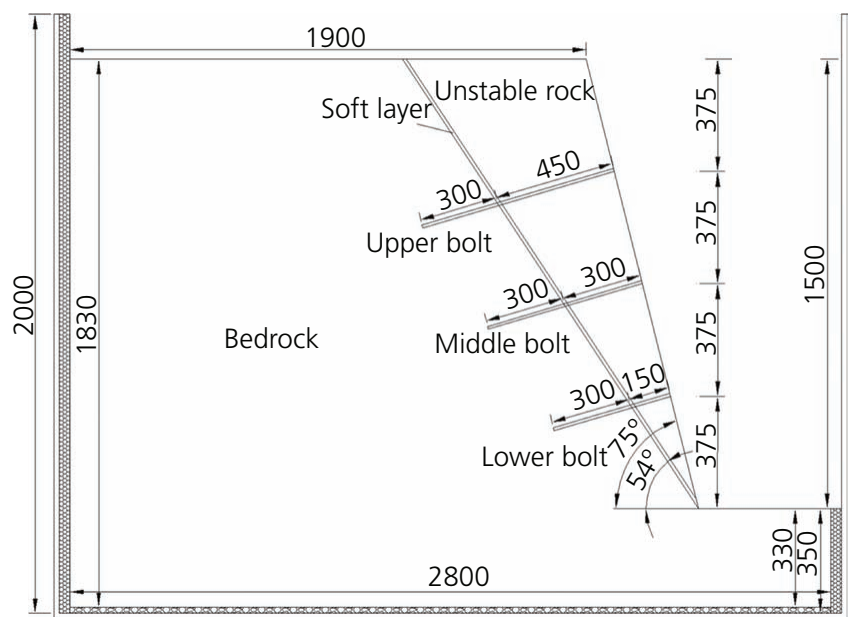

Figure 10. Figure of the anchor stock layout

seismic performance of double-row piles was better. Sun et al. (2019) conducted a seismic simulation shaking table test on the bridge-tunnel lap structure model of high-speed railway based on the similarity theory. The test simulation analysed the dynamic response and catastrophic behaviour of the bridge-tunnel lap structure under earthquake action with the condition of soft surrounding rock. The system composition of the bridge-tunnel lap shaking table model test platform is shown in Figure 11. Gong et al. (2020) conducted a 1:15 scale shaking table model test on the single-span $1000 \mathrm{kV}$ outgoing frame under dynamic coupling action of transmission wires, and explored the influence mechanism of the dynamic coupling action of transmission wires on the seismic response of $1000 \mathrm{kV}$ outgoing frame under longitudinal earthquake action.

In recent years, the shaking table has also been applied in the field of cultural relic protection. Zhou et al. (2015) explored the influence of traditional reinforcement methods on the seismic performance 


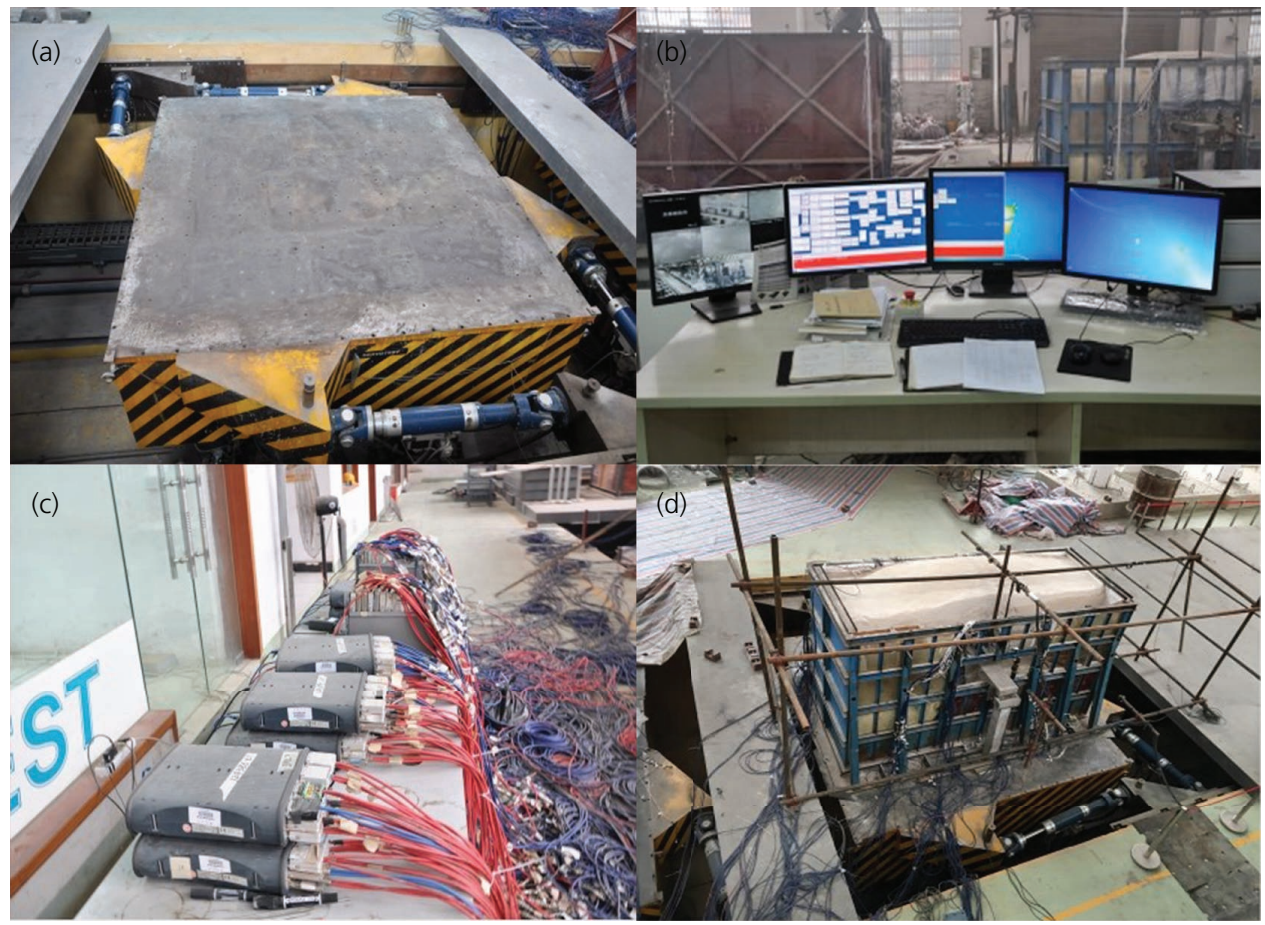

Figure 11. Shaking table model test platform system for the bridge-tunnel lapping: (a) shaking table, (b) operating deck, (c) test data acquisition instrument, and (d) model

of floating cultural relics through a 1:1 model seismic test. The research showed that the large difference between the fundamental frequency and the input seismic wave is one of the main reasons why the earthquake damage is not obvious for the display cases, and pointed out that the application of plastic clay and fishing line to reinforce cultural relics has a better effect on reducing the maximum value of the acceleration response of cultural relics. This study provides a new idea for the protection of cultural relics against earthquake. Ji et al. (2019) carried out a seismic simulation shaker scale model test with the outer brick wall of an ancient building as the object, and the results are clear: it provides a reliable basis for the repair, protection and seismic reinforcement of historic buildings.

\section{Conclusions}

In this paper, a comprehensive analysis and summary are made on the testing methods and technical applications of the construction situation and control technology of the shaking table, at home and internationally, and the following conclusions are drawn:

(i) The construction scale and type of seismic simulation shaking table have changed dramatically. At present, 'electro-hydraulic servotype three-directional 6 degrees of freedom large seismic simulation shaking table' and 'multi-combined shaking table vibration system' have become the mainstream, and the construction of multifunctional shaking table has also become inevitable.

(ii) The control technology of seismic simulation shaking table system is quite mature, and the intelligent control algorithm and parameter tuning and compensation technology can effectively improve the control performance of the system. Neural network, selflearning intelligent algorithm and so on can provide more new ideas for the optimisation and development of shaking table control technology.

(iii) The relevant test methods of seismic simulation shaking table have been rapidly developed, which can provide seismic test technical support for many research fields. The application technology of seismic simulation shaking table can also be further developed towards the direction of 'Internet + ' and 'collaborative test of structural network'.

(iv) In future studies, researchers can try to predict the building damage in disaster areas before the earthquake through 'Internet + shaking table', which helps solve the challenge that the building environment in disaster-prone areas cannot be reasonably optimised and strengthened in advance before the earthquake.

\section{Acknowledgements}

This work is supported by the Graduate Research Innovation Fund of Xinyang Normal University, China (2020KYJJ49).

\section{REFERENCES}

Cai YJ (2018) Research of Control Algorithm for Seismic Simulation Shaking Table. PhD thesis, Tsinghua University, Beijing, China.

Chen RZ and Zhang B (2013) The TVC control technology of shaking table. Technology for Earthquake Disaster Prevention Technology 8(2): 181-188. 
Chen WZ, Jiang GL, Liu Y et al. (2020) Shaking table test on slope roadbed reinforced by bored piles of Sichuan-Tibet railway. Chinese Journal of Rock Mechanics and Engineering 39(12): 2540-2556, https://doi.org/10.13722/j.cnki.jrme.2020.0339.

Gao CH, Ji JB, Yan WM et al. (2014) Developments of shaking table technology in China. Chinese Civil Engineering Journal 47(8): 9-19, https://doi.org/10.15951/j.tmgcxb.2014.08.027.

Gong J, Zhi XD, Shang WN et al. (2020) Shaking table test on $1000 \mathrm{kV}$ frame by considering coupling effect of transmission lines under longitudinal excitations. Chinese Civil Engineering Journal 53(3): 51-59, https://doi.org/10.15951/j.tmgcxb.2020.03.007.

Han S, Cao YW, Deng CH et al. (2018) Research on test for three-axial virtual vibration of liquid rocket engine. Journal of Rocket Propulsion 44(6): $68-74$

Huang HH (1986) Introduction to the development of shaking table. In World Earthquake Engineering (Huang Hao-Hua (ed.)). China Academic Journal Electronic Publishing House, Beijing, China.

Huang HH (2008) Design and Application Technology of Seismic Simulation Shaking Table. Earthquake Press, Beijing, China.

Ji JB, Li ZB, Tang ZY et al. (2012) Velocity synthesis method for shaking table control system. Journal of Beijing University of Technology 38(7): 1032-1035.

Ji JB, Sun LJ, Zhan PY et al. (2014) Control parameters auto-tuning methods of shaking table based on expert experiences. Technology for Earthquake Disaster Prevention 9(4): 882-890.

Ji LP, Liu B and Wang ZL (2019) Experimental study on the seismic performance of ancient city walls. Earthquake Resistant Engineering and Retrofiting 41(3): 126-132.

Kavand A, Haeri SM and Raisianzadeh J and Soltani SA (2021) Seismic behavior of a dolphin-type berth subjected to liquefaction induced lateral spreading: $1 \mathrm{~g}$ large scale shake table testing and numerical simulations. Soil Dynamics and Earthquake Engineering 140: article 106450, https://doi.org/10.1016/j.soildyn.2020.106450.

Li FF, Ji JB, Li XJ et al. (2019) Force feedback compensation control of shaking table system with interaction between shaking table and specimen. Journal of Vibration Engineering 32(4): 685-694, https:// doi.org/10.16385/j.cnki.issn.1004-4523.2019.04.016.

Li JL, Zhang SR, Wang SL et al. (2020) Shaking table tests on the seismic response of a columnless subway station with asymmetric load under bidirectional seismic action. International Journal of Safety and Security Engineering 10(4): 559-566.

Li XJ, Li FF, Ji JB et al. (2018) A new control technology of shaking table based on the jerk. Advanced Engineering Sciences 50(3): 64-72, https://doi.org/10.16385/j.cnki.issn.10.15961/j.jsuese.201800370.

Li ZB, Tang ZY, Zhou DX et al. (2010) Effects on the earthquake simulation caused by the characteristics of the specimen in the shaking table tests-part I: effects on the stability of the system. Journal of Beijing University of Technology 36(8): 1091-1098.

Ling XC (2008) E-Defense research tests. Earthquake Engineering and Engineering Dynamics 24(4): 111-116, https://doi.org/10.13197/j.eeev. 2008.04.005

Luan QL, Chen ZW, Xu JR et al. (2014a) Three-variable control technique for a seismic analog shaking table. Journal of Vibration and Shock 33(8): 54-60, https://doi.org/10.13465/j.cnki.jvs.2014.08.010.

Luan QL, Chen ZW Xu JR et al. (2014b) Three-variable control parameter tuning technology on seismic simulation shaking tables. Journal of Vibration Engineering 27(3): 416-425, https://doi.org/10.16385/j.cnki. issn.1004-4523.2014.03.002.

Ma N, Wu HG, Ma HM, Wu X, Wang G et al. (2019) Examining dynamic soil pressures and the effectiveness of different pile structures inside reinforced slopes using shaking table tests. Soil Dynamics and Earthquake Engineering 116: 293-303, https://doi.org/10.1016/j. soildyn.2018.10.005
Nakashima M, Kato H and Takaoka E (1992) Development of real-time pseudo dynamic testing. Earthquake Engineering and Structural Dynamics 21: 79-92, https://doi.org/10.1002/eqe.4290210106.

Peng DF (2018) Research on control of turntable servo system based on wavelet neural network. Information and Computer (18): 159-160, https://doi.org/CNKI:SUN:XXDL.0.2018-18-063.

Pu XW, Wang LM, Wang P et al. (2020) Study of shaking table test on dynamic response characteristics and failure mechanism of the loess slope. Earthquake Research in China 34(1): 121-135.

Reinhorn AM, Sivaselvan MV, Liang Z et al. (2005) Large scale real time dynamic hybrid testing technique - shake table substructure testing. 2003 Sructures Congress \& Exposition, May 29-June 1, Seattle, USA paper 587

Shen C and Qian DL (2019) Experimental and numerical investigation of the seismic performance of a high-rise building with frame-coretube structure. Structural Engineers 35(5): 164-173, https://doi.org/10. 15935/j.cnki.jgges.2019.05.023.

Shi WX, Bai LG and Han JQ (2018) Shaking table test study on earthquake simulation of circulating fan for nuclear power plants. China Civil Engineering Journal 51(5): 133-138, https://doi.org/10.15935/j.cnki. jgges.2019.05.023.

Soleymani M, Khalatabari SA and Ghanbari SB (2019) Fuzzy-slidingmode supervisory control of a seismic shake table with variable payload for robust and precise acceleration tracking. Journal of Earthquake Engineering 23(4): 539-556.

Sun GC, He S, Fu HL et al. (2019) Study shaking table test method for seismic responses of bridge-tunnel lapped structure in weak surrounding rocks. Journal of the China Railway Society 41(1): $117-125$.

Tagawa Y and Kajiwara K (2007) Controller development for the EDefense shaking table. Proceedings of the Institution of Mechanical Engineers Part I-Journal of Systems and Control Engineering 221(2): 171-181.

Tang ZY, Li ZB, Ji JB et al. (2009) Development in shaking table control system. Earthquake Engineering and Engineering Dynamics 29(6): 162-169, https://doi.org/10.13197/j.eeev.2009.06.001.

Tang ZY, Li ZB, Zhou DX et al. (2010) The effects on the earthquake simulation caused by the characteristics of the specimen in the shaking table tests-part (2): the effects on the replaying precision of the recorded seismic waves and the real-time compensation. Journal of Beijing University of Technology 36(9): 1199-1205.

Tian P, Chen ZW and Jing W (2012) Improved earthquake simulation test method based on adaptive control. Journal of Vibration and Shock 31(9): 49-52, https://doi.org/10.13465/j.cnki.jvs.2012.09.031.

Tongji University (2021) Introduction of multifunctional shaking table laboratory of Tongji University, China. See https://mpstl.tongji.edu.cn/ index (accessed 20/07/2014).

Wan K, Wang P and Zhu DY (2012) Present situation and the development in electro-hydraulic vibration control system. Instrumentation Customer 19(4): 1-5.

Wang S and Lei Q (2020) High precision waveform reproduction of shaking table based on linear active disturbance rejection control. In Proceedings of the 39th Chinese Control Conference. Technical Committee on Control Theory, Curran Associates, NY, USA, vol. 6 , pp. 3610 .

Wang T and Pan P (2018) Research and application of sub-structure mixed test method. Engineering Mechanics 35(2): 1-12.

Wang YH (2009) Research on Shaking Table, South-East University, Nanjing, China.

Wang YH, Cheng WX, Lu F et al. (2007) Development of the shaking table. Earthquake Resistant Engineering and Retrofitting 29(5): 53-56, https://doi.org/10.16226/j.issn.1002-8412.2007.05.013. 
Smart Infrastructure and Construction

Volume 174 Issue 1
Review on the construction development and control technology of the shaking

table

Gao, Wang, Yuan et al.
Williams MS (2001) Dynamic testing of structures-Preface. Philosophical Transactions of The Royal Society A: Mathematical, Physical and Engineering Sciences 359(1786): 1649-1650.

Xie W and Sun LM (2018) Experimental studies on a large-scale full model of a super long-span cable-stayed bridge by using shaking table array system. China Civil Engineering Journal 51(8): 47-59, https:// doi.org/10.15951/j.tmgexb.2018.08.006.

Xu HL, Shi MQ, Zhang X et al. (2017) Research on flight control algorithm of six rotor unmanned helicopter based on PIDNN. Transducer and Microsystem Technologies 36(12): 25-27, https://oi.org/10.13873/J 1000-9787(2017)12-0025-03.

Xu Y, Hua H and Han J (2008) Modeling and controller design of a shaking table in an active structural control system. Mechanical Systems and Signal Processing 22(8): 1917-1923.

Yan JK, Li JZ, Peng TB et al. (2016a) Shaking table tests and numerical analysis for traveling wave effect of a three-tower two-span suspension bridge. Journal of Vibration and Shock 35(7): 44-48, https://doi.org/10.13465/j.cnki.jvs.2016.07.007.

Yan WM, Gao XL, Xie ZQ et al. (2016b) Optimization method for the placements and parameters of displacement-based dampers using artificial fish swarm algorithm. Journal of Vibration and Shock 35(10): 66-72, https://doi.org/10.13465/j.cnki.jvs.2016.10.011
Yan ZX, Liu CB, Long Z et al. (2020) Experimental study on seismic response of anchorage of bedding rock slope with weak laver. Chinese Journal of Geotechnical Engineering 42(12): 2180-2188.

Yang $\mathrm{X}$, Hongxing $\mathrm{H}$ and Junwei $\mathrm{H}$ (2007) Three state controller: design of shaking table in active structural control system. In IEEE International Conference on Control and Automation, Guangzhou, China (Hua H (ed.)). Shanghai Jiao Tong University, Shanghai, China.

Zhang B, Zheng ST, Yang ZD et al. (2013) PSD replication of a shaking table based on adaptive inverse control. Journal of Vibration and Shock 32(20): 151-155, https://doi.org/10.13465/j.cnki.jvs.2013.20. 009 .

Zhang MZ (1997) Study on similitude laws for shaking table tests. Earthquake Engineering and Engineering Dynamics 17(2): 52-58, https://doi.org/10.13197/j.eeev. 1997.02.007.

Zhao H and Chen ZJ (2019) Tianjin University's underwater seismic simulation shaking table array equipment passed acceptance. Tianjin University News, 31 December. See http://news.tju.edu.cn/info/1012/ 49534.htm (accessed 26/10/2021).

Zhou G, Yan WM and Ji JB (2015) Experimental study on a seismic behaviors of a free-standing cultural relic supported by traditional methods. Sciences of Conservation and Archaeology 27(2): 63-72, https://doi.org/10.16334/j.cnki.cn31-1652/k.2015.02.013.

\section{How can you contribute?}

To discuss this paper, please email up to 500 words to the editor at journals@ice.org.uk. Your contribution will be forwarded to the author(s) for a reply and, if considered appropriate by the editorial board, it will be published as discussion in a future issue of the journal.

Proceedings journals rely entirely on contributions from the civil engineering profession (and allied disciplines). Information about how to submit your paper online is available at www.icevirtuallibrary.com/page/authors, where you will also find detailed author guidelines. 